\title{
Erlitou and Xia: A Dispute between Chinese and Overseas Scholars
}

\section{Chen Chun}

Fudan University

\section{Gong Xin}

Shanghai Museum

\begin{abstract}
Based on a review of the excavation and research at the Erlitou site at Yanshi in Henan and the Xia Culture, this article explores the causes of dispute between Chinese and overseas scholars concerning the study of early Chinese states, in terms of epistemology, archaeological paradigms, utilization of historical records, reasoning method and normative versus ideographic approaches. The argument of this article is that this dispute occurs not only from the differences in academic traditions, but also the methodological backwardness caused by a lack of international exchange.
\end{abstract}

\section{INTRODUCTION}

The concept of the Xia Dynasty has played a crucial role in the exploration of the origin of incipient states in China. Since hard evidence for the existence of the Shang Dynasty was found at Yinxu, the substantiation of the Xia Dynasty is naturally the next item on the agenda. As early as the middle of the twentieth century, historian Fan Wenlan purported Xia to be the first dynasty in Chinese history on the basis of historical documents such as Shang Shu and the Records of Historian (Shi Ji) (Fan 1994: 31 ). Following textural research into 'the residential area of the Xia ethnic group or the Xia tribe', archaeologist Xu Xusheng suggested that the Luoyang plain in the central Henan Province and the lower reaches of the Fen River in the southwestern Shanxi Province might have been two potential areas where the Xia Dynasty might have existed and so went to Henan to conduct field surveys (Xu 1959: 593-596). Having discovered the remains of the early Shang at the Erlitou site at Yanshi, he suggested further archaeological surveys and excavations might be conducted in western of Henan and southwestern Shanxi. In 1959, a field team from

Social Evolution \& History, Vol. 17 No. 2, September 2018 235-257

(C) 2018 'Uchitel' Publishing House

DOI:10.30884/seh/2018.02.13 
the Institute of Archaeology, Chinese Social Academy of Sciences at Luoyang excavated the site at Erlitou and discovered three layers of stratigraphy from the late Longshan to the early Shang (Field team of Luoyang from the Institute of Archaeology 1961: 85).

Following these discoveries, several articles were published, arguing that the Erlitou Culture could be also be the Xia Culture. For example, archaeologist Tong Zhuchen argued that geographic location of Xia could be ascertained from the historical document Nation Saying Zhou Saying (Guo Yu: Zhou Yu) which stated 'at that time, the collapse of Xia occurred simultaneously with the drying up of the Yi and Luo Rivers'. Tong also corresponded the statement in Bamboo Annual-Xia (Zhushu Jinian: Xiaji) 'the $\mathrm{Yu}$ to the Jie lasted seventeen generations, with or without kings, and totaled 471 years' with two radiocarbon dates from the Erlitou site, then spatially and temporally fixed that Erlitou was the capital of the Xia Dynasty. He listed the foundation of the palaces, the bronze vessels and burials discovered at Eelitou as being characteristic of that of a slave state (Tong 1975: 29-33). Due to the persistence of leading archaeologists, the controversy caused by some objections to these findings faded away. For instance, archaeologist Zou Heng prevailed over all dissenting views and agreed that the Erlitou Culture was the Xia Culture (Zou 1980: 104). Such academic consensus meant that 'doubting the Old and distinguishing the false' was a thankless task. Ancient legend and documents could be employed needless any criticism. Some scholars optimistically claimed that the negation of the existence of the Xia Dynasty had already been exhausted through several decades of painstaking scholarship, and as a result, nowadays those scholars who negated the Xia were indeed few in number (Xie 1995: 93).

After 1995, stimulated by the achievements in archaeological dating in Egypt and Mesopotamia, the State Council decided to start 'The Xia, Shang and Zhou Dynasties Chronology Project' by organizing an interdisciplinary collaboration between astronomy, archaeology, history and paleography. This approach combined with advanced dating techniques promoted the study of three dynasties including the Xia, to its zenith. In 1999, the completed Project was accepted and awarded with one of the ten great achievement prizes for science and technology in China in the same year. Its goal was to establish a scientific chronology of the Xia, Shang and Zhou dynasties through multi-disciplinary collaboration, based around nine subjects for investigation and forty-four sub-topics. The publication of the project was followed by commendation in China but suffered incisive criticism abroad. This highlights the tremendous differences in paradigm and research methodology between Chinese and the Western scholars.

'The Xia, Shang and Zhou Dynasties Chronology Project' not only establishes a factual existence of the Xia, but also lists a chronological 
table of the dynasties as well as the lineage of kings of the Xia Dynasty. Scholars who maintain this position put forward four reasons to support their conclusion. (1) The written records of the Zhou Dynasty support the argument that western Henan and southern Shanxi was the area where the Xia ethnic group had inhabited. Due to geographic collusion, it is highly possible that the Erlitou Culture is also representative of the Xia Culture. (2) The discovery of 'palaces' indicated the existence of a nation-state. (3) The $\mathrm{C}^{14}$ dating results can prove that Erlitou existed within the scope of the Xia. (4) Since the Shang Dynasty in Sima Qian's 'Records of the Historian' (Shi Ji) has been proved reliable, the records of the Xia may be assumed to also be reliable (Chen 2003).

However, these arguments cannott wholly convince scholars, both in China and abroad, who still hold reservations. This research should not only hypothesize the existence of the Xia, but has to prove it. The earliest written record of Xia appeared during the Zhou Dynasty. Furthermore, there was no sign at all about the Xia on the oracle texts of the Shang. Thus, there are suspicious that the Xia is a fabrication by later generations. Due to the absence of any written evidence dating from the Xia period, this issue could not be approached with pre-assumed suppositions but has to be studied independently through archaeology. Unfortunately, so far Chinese archaeologists have not yet thoroughly exploited archaeological materials and use all the information extracted from their data to fully explore the issue. They have thus restricted their researches within the confines of comparisons of excavated artifacts to identify the Xia Culture, doubtlessly in order to confirm historical documents by using the archaeological data.

The problems revealed by the study of the Xia Culture and 'The Xia, Shang and Zhou Dynasties Chronology Project' include not only the differences in stances but also divergence in research orientation and paradigms. For instance, establishing the existence of the Xia is closely related with the affirmation of the history of Chinese civilization of five thousand years and the propagation of China's sense of national pride. Therefore, the project was also called 'the Project of Cohesion'. If the research has such obvious pre-inclination, it is problematic to guarantee academic neutrality when scholars are drawing their conclusions. M. Johnson pointed out that interpreting the past is always a political act and always has political resonance. If scientific neutrality is a myth, then our statements about the past are never objective judgments detached from the real world and jumbled mixture of political and moral judgments (Johnson 1999: 107). Influenced by such values, some unusual sentiments permeated normal academic discussions. For instance, critiques that some western scholars had made of 'The Xia, Shang and Zhou Dynasties Chronology Project' were regarded as 'imperialist' and 'hostile' speeches and bitterly attacked. Some Chinese scholars maintained their negative attitude and claimed, 'as to individual foreign scholar who argues that the Xia Culture was merely a legend, let her 
do as she pleases. It won't affect our studies of China's ancient history. We don't need her to solve the chronology of China's ancient history' (Tian 1994: 33). Such attitude and opinion are obviously contrary to scientifically based argumentation.

It should be conceded that the exploration of the origin of the Chinese civilization is an important component of international ancient civilization research, and furthermore area where we could potentially make our most valuable contribution to the global field of social sciences. Any unbiased scholars would welcome and praise the Chinese academic achievements. However, on the other hand, like being awarded the Olympic Games, if we want the world community to accept our conclusions, we have to be in accordance with international academic standards and norms. Due to the fact that Chinese scholars know little about current international advances, this has suffered in a limited knowledge base, narrow perspectives, and the continued use of obsolete methods. Therefore, there are many problems in their research. Using out-of-dated standards to apply for the nomination of world records fails to be accepted by world community.

Having explored the debate on Erlitou-Xia relations in terms of academic freedom and political orientation, Liu Li argues that the discrepancy of this issue between Chinese and overseas scholars should be attributed to traditional rather than ideological or political reason (L. Liu 2009: 841842). This paper seeks to make a review of the studies of Erlitou and Xia, examining some crucial issues from the reference point of international paradigm, in order to improve our research in this area.

\section{RETROSPECT}

The following is a review of the studies of the Erlitou and the Xia Culture from six perspectives. This leads on to an analysis and discussion concerning for what reasons gave rise to such controversy between Chinese and the western scholars.

\subsection{Field Surveys and Excavations}

After the discovery of the Erlitou site by Xu Xusheng and test excavation conducted by the Institute of Archaeology, eight excavations were subsequently conducted by the field team from Luoyang between 1960 and 1964. Three separate phases were identified from the basis of pottery classification and relative dating. The age of the Erlitou site was placed between that of the Longshan Culture of Henan and the Shang Culture of Erligang in Zhengzhou (Field team of Erlitou from the Institute of Archaeology 1965: 223-224).

In 1974, the field team of Erlitou from the Institute of Archaeology uncovered the first palace foundation (Field team of Erlitou from the Institute of Archaeology 1974: 238-48). In 1977, the second palace foundation about 
$150 \mathrm{~m}$ northeast of the first foundation was unearthed. On the basis of rammed earth layers and recovered potsherds, it was proposed that the second foundation of 'palace' was built in the third phase of the Erlitou site and abandoned in the late fourth phase of the Erlitou or the early Erligang phase. In addition, a large tomb dating from the same phase was discovered to the north of the palace (Field team of Erlitou from the Institute of Archaeology 1983: 206-16). This excavation furthered the division of the Erlitou Culture into four distinct phases.

In 1980, a third excavation was conducted out at the Erlitou site in coordination with a construction project. The cultural characteristics of the second, third and fourth phases were identified on the basis of the stratigraphic context and pottery typology (Field team of Erlitou from the Institute of Archaeology 1980b: 119-205). It was realized that the fourth phase was contemporary to the lower layer of Erligang and had developed directly to the upper layer of Erligang (Field team of Erlitou from the Institute of Archaeology 1984: 582-593). A number of excavations were conducted during the 1980s by the field team of Erlitou from the Institute of Archaeology, yielding many discoveries of residential foundations, artifacts, tombs and ash pits from different phases (Field team of Erlitou from the Institute of Archaeology 1982: 1085-1094, 1108; 1987: 294-303).

Until to the late-twentieth century, the research at Erlitou was basically carried out by using stratigraphic and typological approaches. Thus fieldwork emphasized the division of layers and phases and the identification of cultural characteristics. It appears that the selection of digging spots lacked a problem-solving and hypothetic-deductive orientation. Such sketchy excavation methodology has hampered efforts by both Chinese and overseas researchers to further understand the scope, importance, overall circumstance and process of development of the site.

Not until 1999 did the Erlitou Team from the Institute of Archaeology, Chinese Academy of Social Sciences started to take settlement archaeology as the focus of their fieldwork. Four years of survey, probing the soil with rods, and excavation offered a better understanding of the scale, structure, layout, and paleoenvironment of the site, which allowed to further explore the relationship between the Erlitou site and its natural environment, the position of the site within the settlement network, and the social organization of the settlement community (Xu, Chen, and Zhao 2005: 484-493).

From 1997 to 2002, an international team collaborated by experts from China, the U.S., England, and Australia conducted an intensive survey of settlement patterns at the Yiluo River Basin where Erlitou site was located. Combined with geoarchaeology research, archaeobotanic study and pottery analysis, this survey was trying to explore such major issues as regional settlement patterns, process of social complexity, population 
fluctuation, group conflict, environmental change, land utilization, agricultural productivity level, craft specialization, regional interaction, and political concentration. The survey covered about 219 square kilometers, across six archaeological periods from the Peiligang period $(6,500-$ $5,000 \mathrm{BC}$ ) to the Shang and Zhou Dynasties (1600-221 BC) (Chen X. et al. 2003: 484-493).

Based on the survey of settlement pattern s on the Yiluo River, Qiao $\mathrm{Yu}$ estimated population changes in different periods according to the settlement areas. With the aid of GIS technique, she reconstructed the productivity level and land-use rate of the catchment area in different periods to explore the relationship between population and social complexity. The research showed that the settlement stratification had paralleled with the population growth. There were two peaks in population growth at the Yiluo River Basin. The first appeared during the mid-late Yangshao period with the appearance of two level hierarchy of settlement pattern; the second appeared in the late Longshan period and continued to the Erlitou period, with the emergence of three level hierarchy of settlement pattern. The research also found that even in the period with largest population, the total land-use rate of averaged 46 per cent. Qiao Yu argued that the developments of settlement patterns and social complexity at the Yiluo River Basin might not have been caused by population pressure (Qiao 2010: 435-453).

Liu Li examined the change of settlement patterns in the Central Plain from a broader perspective and found several significant changes appeared during the transitional period from the Longshan to the Erlitou periods: (1) The number of sites decreased sharply; (2) The settlement scale increased dramatically, indicating that the population concentrated centripetally; (3) The settlement hierarchy upgraded from three to four levels ; (4) A single center controlling over other settlements was formed, which replaced the coexistence of multiple competitive entities; (5) The appearance of bronze ritual vessels; (6) Multiple pottery types were replaced by two Erlitou types. These could be assumed that the expansion of the Erlitou culture might have happened in phases II and III, during which time Erlitou site was in dominant position, suggesting the formation of an early state in the region (Liu L. 2004: 226-229).

\subsection{Cultural Periodization}

So far, any dialogue about the Erlitou and the Xia Cultures has been basically based on a series of ill-informed, brief excavation reports. Periodization has been regarded as the most important part in the chronological work. According to the stratigraphic examinations of many different sites such as Xinzhai in Xinmi City, Donggangou in Luoyang, Meishan in Linru, it has been confirmed that the layers of Erlitou overlie those of Henan's 
Longshan Culture. At some sites such as Erlitou at Yanshi, Shaochai at Gongxian and Luodamiao in Zhengzhou, it can be seen that the layers of the Erlitou Culture are covered by the Erligang Culture. Thus, the Erlitou Culture is sandwiched between Henan's Longshan Culture and Zhengzhou's Erligang Culture. Some scholars divided the Erlitou Culture into three phases. In 1974, the field team of Erlitou put forwards four periodic division for the Erlitou Culture based on data unearthed from two palace sites.

During two excavations at the Xinzhai site in 1979 and 1999, researchers claimed to have identified a layer of a distinct culture that existed between Henan's Longshan Culture and the first phase of the Erlitou. They called it 'the Xinzhai phase' and subdivided it into two sub-phases. Xinzhai sub-phase 1 belongs to the remains of the late Longshan Culture. Xinzhai sub-phase 2 probably belongs to a transitional interval between Longshan and Erlitou. Later, some scholars suggested that Xinzhai subphase 2 should be regarded as part of the Erlitou Culture and renamed it 'the Erlitou Culture of the Xinzhai phase' or 'the first phase of the Erlitou Culture-Xinzhai type' (Li 2002: 37-41).

On the basis of the archaeological data from the second palace discovered at Erlitou, Zheng Guang argued that there should be a fifth phase added after the four phases of the Erlitou Culture, or called 'the lower layer phase of Erligang' (Zheng G. 1985: 18-24). However, due to obvious differences between remains from the late phase of Erlitou and those from Erligang, the existing view of the four periodizations was commonly accepted.

It is necessary to conduct periodization for prehistoric sites based on stratigraphy and typology. However, in the end it is only a subjective judgment based on a typological comparison of artifacts and thus differs with individual opinion. Although temporal division based on artifact typology can be used to examine cultural change, this approach is inadequate for the investigation into to process of social change such as origin of early states. This is to say, even if we fix the demarcation between the Erlitou Culture and the Longshan Culture of Henan, this doesn't prove that it was the beginning of the Xia Dynasty.

\subsection{Cultural Characteristics}

Since the Erlitou Culture has been generally accepted as being equal to the Xia Culture, a series of artifacts unearthed from the Erlitou-type sites have been listed and described as being the cultural characteristics of the Xia. The main standard of measurement came from ceramic artifacts since a range of unique artifacts had been excavated at Erlitou including round bellied jar, dou, he, bevel walled basins, jue, flat bottomed basins, small mouthed urns, containers with tiled legs, gu and so on. Although there were some differences between styles from the early to later phases, as a group these types of artifacts are either absent or limited in other ar- 
chaeological cultures, and therefore regarded as diagnostic artifacts of a distinct Xia Culture (Liu X. 1986: 48-54).

Zou Heng summarized the three diagnostic characteristics of the Xia Culture thus: (1) most pottery has a round bottom; (2) the existence of a square-shaped pottery ding with the appearance of a bronze vessel, indicating the use of bronze casting during the early Xia; (3) ritual vessels including gu, jue and he (Zou 1980: 135).

Other scholars referred to cultural characteristics of the Xia in terms of the tombs dating from this period. Tombs of the first phase were characterized by small vertical rectangular pit-graves which increased in number during the second and third phases. Medium and large vertical rectangular pit-graves appeared during the second and third phases. Some contain a second platform and many burial objects. Tombs of the fourth phase followed previous burial patterns but decreased in number and quality. Tombs dating from the first period share some characteristics of the Longshan Culture unearthed in Henan and Shanxi. These tombs resemble those from the lower layer at Erligang. By the second and third periods tombs had developed unique characteristics representing the zenith of the Erlitou Culture (Zheng R. 1994: 63-81).

Generally speaking, the Xia had been identified and defined through a group of diagnostic artifacts, including cooking utensil like ding, jars with a round belly and rims extending outwards, eating dishes such as basins with a deep belly, basins with three legs, basins with a flat bottom, dou, jars with a long neck and a small mouth, urn, drinking utensils such as gu, jue and he (Zhu 1998: 16-22).

In the November of 1977, Xia Nai provided a definition of the Xia Culture at the Conference of the Excavation at the Gaocheng site in Dengfeng, which was that archaeologically the Xia Culture 'should be referred to the culture of the Xia nationality during the Xia Dynasty'. It should be mentioned that an archaeological culture as defined by artifacts is not necessarily equal to an ethnic group. A dynasty or a state might contain different ethnic groups. Due to the fact that ethnicity can't be identified archaeologically, artifact types become main criteria to define the Xia Culture. According to current evidentiary methods, Chinese scholars infer that the following: the Erlitou Culture $=$ the Xia Culture $=$ the $\mathrm{Xia}$ ethnicity $=$ a group of diagnostic artifacts $=$ the Xia State $=$ the territory of the Xia. As we will discuss later, such inference has many faults.

\subsection{Cultural Category}

Archaeological remains of the Erlitou Culture have been uncovered throughout the province of Henan, the eastern part of Shaanxi and southern Hebei. From the materials available, they can be divided regionally into the Erlitou subtype of western Henan, the Dongxiafeng subtype of southwestern Shanxi, the Eastern Henan subtype of southern Hebei and northern Henan and the Xiawanggang subtype of southern Henan. Among 
these, sites which belong to the Erlitou subtype of western Henan are greatest in number. Thereupon, owing to the fact that the Erlitou site is the most typical of this period, the Erlitou site becomes representative of the Erlitou Culture as a whole.

Since the establishment of the cultural category represented by the Erlitou site, scholars have begun to discuss the attributes of the Erlitou Culture and its relationship with the Xia. Although the Erlitou Culture was regarded as being the Xia Culture, question of whether the cultural items from all four phases can be included into the Xia Culture remains a point of controversy. In 1977, Xia Nai summarized the four different viewpoints of this debate: (1) The relics of late Henans's Longshan Culture and four phases of the Erlitou site, all belong to the Xia. (2) The relics of the late Henans's Longshan Culture and the first and second phases of Erlitou belong to the Xia. (3) The material culture of the first and second phases of Erlitou belongs to the Xia, while those of the third and fourth phases belong to the Shang. (4) The four phases of Erlitou all belong to the Xia, but those of the Longshan Culture do not (Xia 1978: 32-33).

Since the 1980s, the radiocarbon dating technique has been commonly used for archaeological dating in China. By comparing that assumed from written records to the C14 dating results of each phase of Erlitou, it was verified that phases of the Erlitou Culture are all located within the Xia period. Using the first year of the Gonghe text of the Western Zhou $(841 \mathrm{BC})$ as the starting point, in addition to historical records such as the Records of Historian, the Bamboo Annual, the Han Annual, Shang Shu, and inscriptions on the bronze vessel Li Gui, the academic community estimated that King Wu had overthrown the Shang in 1075 BC. They calculated the length of the Shang chronology based on the Records of Historian, Record of Primary Study (初学记), and the Zhushu Jinian (竹书纪 年; Bamboo Annual), and then calculate the Xia chronology based on the textual sources Yi Wei, Zhushu Jinian and The Grand History (路史). It is estimated that the chronology of the Xia ranged between 2061 and $1554 \mathrm{BC}$. The $\mathrm{C} 14$ dating results show that four phases of the Erlitou Culture ranged between 2000 and $1600 \mathrm{BC}$. Thus the Erlitou site can be fixed within the estimated time range of the Xia (Zhuang 1990: 1-7).

\subsection{The source of the Xia Culture}

After the agreement about the Xia's existence, the academic community started to investigate its origins. The chronological table of the Xia, Shang and Zhou Dynasties published in 2000 indicates that the first year of the Xia Dynasty was $2070 \mathrm{BC}$. If year of $1900 \mathrm{BC}$ was the begging of the first phase of the Erlitou Culture, there is an interval of about two hundred years between them. This means that the beginning of the Xia Dynasty might be earlier than the first phase of the Erlitou. 
The excavation at the Wangchenggang site of Gaocheng in Dengfeng City in the 1980s attracted people's attention to the source of the Xia Culture. Rammed earth walls, rammed earth foundations of dozen large buildings of and evidence for the use of bronze vessels belonging to the middle and late Longshan periods were found (Institute of Cultural Relics of Henan \& Department of Archaeology of Museum of Chinese History 1983: 8-16). Its location is close to the capital of King $\mathrm{Yu}$, a ruler of the Xia according to historical documents. Artifacts unearthed at the site are similar to those of the first phase of the Erlitou. Also, the size of buildings was quite large (An 1983: 1-7). In addition, its C14 dating ranges from 2190 to 1965 BC, corresponding to the Xia chronology (Fang 2001: 4650). At that time, it was suggested that these ruins of the late Longshan might have been 'Yangcheng, the capital of Yu' as mentioned in historical records. Having compared the distribution of sites, artifacts, architectures and burials between the late Longshan Culture, the Erlitou Culture of Xinzhai type and the Erlitou Culture itself, some scholars argued that the Longshan and the Erlitou Culture had developed along one continuous line. The Xinzai phase formed the interval between them (Zhao 1986: 119). It refuted the argument held by some senior archaeologists in the 1970s that there were big differences between the artifacts of Longshan and Erlitou, and thus they could not be the same cultures (Zou 1979: 6469; Wu 1978: 70-73).

Many scholars consider that the Wangwan type of Henan's Longshan Culture and the Erlitou Culture were two archaeological cultures which shared similar attributes. The Erlitou Culture only represents the middle and late phases of the Xia Culture. The late Longshan Culture was the early Xia Culture.

Recently some scholars furthermore argued that the Erlitou Culture was actually not the continuation of Henan's Longshan Culture. It was a new culture that was mixed with cultural traits from both the third phase of Wangwan and surrounding cultures. Thus, Erlitou and Longshan are two separate cultures. They argued that there were obvious differences between cultural remains of the first period of Erlitou and those of the third phase of Wangwan. Cultural remains that had the characteristics of Erlitou dating from the third phase of Wangwan are much rarer than those from the first phase of Erlitou (Li 2002: 39-41). Therefore, the origin of the Xia could be located in the first phase of Erlitou.

\subsection{The Demarcation between the Xia and Shang}

Another issue comparable to that of the origin of the Xia Culture is the demarcation between the Xia and the Shang Dynasties. There are two viewpoints on the issue of the four phase division of Erlitou. The first version suggests that both the first and second phases belong to the Xia Culture, while the third and fourth phases to the Shang Culture. There- 
fore, the interval between the second and third phases of Erlitou was the boundary of the Xia and Shang. The second version argues that four phases of Erlitou are continuous and the interval between the fourth phase and the earlier phase of Erligang was the boundary between the Xia and Shang.

Following typological analysis, scholars concluded that there was no significant difference in the form of the artifacts from the early (the first and second phases) and late (the third and fourth phases) Erlitou. Basically they belong to the same category. Some artifacts, such as deep-bellied jars, round-bottomed basins, li and zun with a big mouth, from the lower layer of Erligang show little difference from those from the fourth phase of Erlitou. Some artifacts however show great difference. For instance, basins with a flat bottom, containers with tile legs, gang, zeng, gu and he of the late Erlitou are all absent from the lower layer at Erligang. Some common artifacts from the late Erlitou such as jue, gui, urns with a small mouth and jars are less frequently found in the lower layer at Erligang. Some appearing in the lower layer at Erligang, such as li and jia are very scarce in the late Erlitou (Zhao 1986: 12-14).

Zhao Zhiquan argued that the Erligang Culture might have directly developed from the Erlitou Culture. The evidence for this is as follows: (1) pottery types of the fourth phase of Erlitou and Erligang are basically the same. (2) Both architectural and burial patterns are similar. (3) Some bronze objects, such as ge and jue, are similar (Zhao 2000: 29). On the other hand, Cheng Pingshan and others argued that while the Erligang Culture contained many cultural factors of Erlitou, some artifacts still manifest large differences in both style and type. The most importantly, some diagnostic artifacts of Erligang were absent at Erlitou. In addition, the Erligang Culture beyond western Henan shows further difference in patterning. Therefore, the Erligang Culture might have partially overlapped the Erlitou Culture in some areas, absorbed some of the Erlitou as well as other influences and then developed into a new culture (Cheng 2001: 88-93, 105). Despite this controversy, most scholars agreed that the interval between the fourth phase of Erlitou and the lower layer of Erligang was the demarcation between the Xia and the Shang Dynasties.

Some scholar tried to search for the demarcation between the Xia and the Shang Dynasties in terms of city ruins. Historical documents claim that Jie, the last king of the Xia, was overthrown by Tang, the first king of the Shang. Thus, if the capitals either of Jie or Tang can be located, we may be able to determine where the boundary of two dynasties lies. Due to the difficulty in locating the Xia capital, much attention has been paid to the determination of the early Shang capital. An early Shang city at Shixiangou in Yanshi has attracted much attention. Although this city was smaller than that found in Zhengzhou, it was one of many early Shang cities and might 
provide a marker for the demarcation between the Xia and the Shang (Li B. 1986: 44). Recently, it has been argued that the Shang city at Yanshi was precisely this boundary, due to the fact that the city was very close to Erlitou both temporally and spatially. It was highly likely that the Shang had paralleled with the Xia, then expanded and finally conquered the late Xia (Yang 2002: 102-106).

Some historical documents such as Shang Shu, Analects of the State, and the Bamboo Annuals mentioned that 'Jie fled to his southern lair', 'Jie of the Xia lost his support and took shelter in northern frontier'. Using these written records as the guidance along with occasional artifacts with an Erlitou style unearthed from the Xuejiagang site in the area of Yangtze and Huai Rivers, the Doujitai site at Shouxian and the Xiajiadian site in the north, some scholar suggested that period in which the cultural traits of the Xia appeared in the Yangtze and Huai river valleys, Shanxi, Hebei and Inner Mongolia could have also been the transition of the Xia and Shang (Du 1993: 12-18).

Like searching for the source of the Xia Dynasty, identifying the time the Xia was conquered by the Shang similarly follows stratigraphic and typological approaches. In fact, the emergence of a state and dynastic change has nothing to do with change in the form of artifacts. Without criticism, it is unwise to interpret archaeological discoveries entirely based on historical documents. The reality of the story that Jie fled is unreliable, and political events or accidents have nothing to do with the distribution of daily utensils. It is unwarranted to define the boundary between the Xia and Shang by linking the two together.

\subsection{Study of City Sites}

After the discovery of the Erlitou site, some scholars referred it to as an early Shang city. This triggered the debate of 'West Bo' and 'Zheng Bo'. Scholars who regarded the third and fourth phases of Erlitou as belonging to the early Shang had been arguing that the palace of the third phase at Erlitou might have been King Tang's 'West Bo' of the Shang. Those who regarded all four phases at Erlitou as the Xia Culture had mentioned that Erlitou might have been 'Zheng Bo'. So, the Shang city in Zhengzhou might have been 'West Bo' of King Tang's capital (Zhao 1978: 9-11, 13).

With the discovery of the Shang city at Yanshi, positions of both groups changed. The 'West Bo' camp split into three versions. The scholars who argued for of 'Zheng Bo' also divided on the issue of the Xia capital. Some argued that two palaces at Erlitou might have been the capital 'Zhu Xun' of King Taikang, while others referred them as dating from the reign of King Shaokang. Others dated the first phase of Erlitou to the reign of King Shaokang and the third phase to the reign of King Jie. Some did not correspond the historigraphical age of kings of Xia to the periodization of 
the Erlitou Culture, and generally referred the Erlitou site to the capital 'Zhun Xun' of the Xia (Zou 1990: 1-12).

Some discussions focused on which city of the Xia corresponding to the Erlitou site. According to written records, the capitals or cities where kings of Xia had lived include King Yu's Ji, Yang Cheng and Ping Yang; King Qi's Xia Yi; King Taikang's Zhun Xun; King Xiang's Shang Qiu; King Houyi's Zhun Xun; King Shaokang returned to the city of Xia Yi before moving to Yuan; King Zhu's Lao Qiu; King Yinjia's Xi He; while King Jie lived in Zhun Xun again. Due to thin sediment and inferior material in the first phase at Erlitou, some scholars argued that the site might have only been a common settlement. Although the second phase was short in duration, its sedimentary layers were is fairly thick, indicating a growth in population. Palaces and rich tombs appeared during the third phase but disappeared in the later phase, indicating the capital moved to another place. The fourth phase lasted only a very short time but the palace was again existed during this time, probably indicating the capital was rebuilt. Therefore, the Erlitou site was probably the capital of King Shaokang's 'Xia Yi'. They further claimed that Zhun Xun might have been Xia Yi, where King Shaokang recovered his reign. The site at Shixiangcheng might have been 'West Bo' of King Tang's capital. According to historical documents, 'West Bo" was rebuilt on the foundation of King Jie's capital, therefore this city site was probably another Zhun Xun built by King Houyi (Zheng G. 1985: 18-24).

Zhao Zhiquan believed that Erlitou was a capital of the late Xia Dynasty and regarded the Shang city at Yanshi as a new capital built in the center of the Xia reign. He did not explicitly correspond Erlitou to any capital of the Xia Dynasty (Zhao 1987: 196-204).

So far, the discussion of the site of the city at Erlitou has been confined to corresponding archaeological discoveries with historical documents. Due to the fact that early historical documents are not always factual, all discussions and conclusions can't be accepted as the truth.

\section{DISCUSSION}

Why do the studies of Erlitou and the Xia Culture arouse such fierce dispute between Chinese and overseas scholars? This will be discussed from five perspectives, including scientific epistemology, archaeological paradigm, and study of historical documents.

\subsection{Cognitive Approaches}

Although the study of the origin of early states in China is considered to be a scientific exploration, most participants are historians and archeologists. In terms of the methodology, study is still a branch of historical research. Therefore, the dispute on this issue between Chinese and overseas scholars is best regarded as a difference of epistemology rather than of personal positions. 
K. C. Chang once pointed out that Chinese traditional history inclines to use the selection of historical data and descriptions to express the historian's subjective judgments. Its main approach is to 'explain history based on subjective judgments'. While this methodology based on historical data and textural research was criticized during the 1930s and 1940s, it has held sway up to the present (Chang 2011: 1-2). We can perceive this strong orientation of subjective judgment everywhere in the study of Erlitou and Xia.

In contrast, however, the epistemology of modern sciences in the West emphasizes objectivity of the research and tries as far as possible to avoid subjectivity. American anthropologist M. Harris pointed out that science is a unique contribution of Western civilization. Science is a way of knowing that has a uniquely transcendent value for all human beings. In the entire course of prehistory and history only one way of knowing has encouraged its practitioners to doubt their own premises and to systematically expose their own conclusions to the hostile scrutiny of nonbelievers (Harris 1979: 27). For this reason, proper critical thinking is not only a principal feature of science, but also the basic method of academic research.

This epistemological difference between Chinese and overseas scholars is just what has led to such tremendous controversy about certain conclusions or opinions. For example, in the face of the criticism of the factuality of the Xia Dynasty and whether Erlitou was really Xia being unable to provide more convincing evidence, Chinese scholars often defended themselves through the consensus in their own community. They barely realize that subjective belief of individual scientists or even consensus in the scientific community cannot endow scientific knowledge with truth. The truth of scientific knowledge is not derived from faith or agreement, but comes from correct reflection of objective reality (Zhang 1988: 2-3).

As far as normal scientific procedure is concerned, research initiated from questions and doubts is the first key of scientific exploration. Thus, both 'doubt' and 'thinking' are the original dynamics of scientific exploration (Lin 1986: 36-40). In terms of the study of Erlitou and Xia, research hypothesis have been entirely put forward on the basis of written records. Scholars have little sense of critical evaluation of either written records or their own judgments. In the face of critiques, they often sulkily disallow any validity. This is obviously contrary to correct scientific attitude. If our premises and conclusion admit of no contention, how can such achievements be accepted by the international community?

\subsection{Archaeological Paradigm}

To date, Chinese archaeologists have employed the culture-historical approach in the study of Erlitou and Xia. This paradigm was advanced by Gordon Childe in the 1920s and accepted world-widely during the early 
of the twentieth century. This method uses typology to lump assemblages or sites yielding same artifacts together to establish an analytical unit identical to the concept of culture in ethnography. Childe once believed that the similarity of material culture would occur when people or ethnic groups shared the same lifestyle. He argued that people who share same the archaeological culture must have spoken same language and had same ideology and same social and political identity.

In the mid-twentieth century, this paradigm was challenged by many scholars including Childe himself. Archaeologists have finally realized that an archaeological culture didn't necessarily correspond to a social unit, such as a tribe or an ethnic group since the distribution of material culture and the scope of social or political organization are seldom consistent. Childe correctly pointed out that defining an archaeological culture totally based on typology without considering their social factors would risk splitting different sectors of a community into different cultures. Similarly, it can't be proved that people who share similar material cultures have same social identity, just like those who possess different material culture might also share the same social identity. It is further noteworthy that in a complex society such as incipient states, rulers and common people might have had different origins. Thus we have reason to consider them totally different ethnic groups. Therefore, archaeologists found that the concept of archaeological culture is suitable to study small, sedentary and isolated prehistoric groups. Due to the fact that social and economic difference in a complex society would cause cultural diversification, archaeological culture becomes an irrelevant measurement to study these communities (Trigger 1978: 106-107).

Due to the faults in this paradigm, the typological approach lost its popularity from the mid-twentieth century onward and the social approach, based on system theory and settlement archaeology started to flourish. Archaeological paradigm has shifted from historiographical research to the study of cultural process. Due to a lack of academic exchange, the archaeological community in China is unfamiliar with the paradigm revolution in Western archaeology since the 1960s and still employs methodology that prevailed in the early twentieth century. Among the critiques on 'the Xia, Shang and Zhou Dynasties Chronology Project', some Western scholars pointed out that archaeological method employed in China is obsolete, resembles Western archaeology during the 1930s (Liu X. 2001). This criticism should not be seen as a deliberate depreciation.

In the research of the early states, Chinese archaeologists are not fully aware of three levels of difficulty in archaeological research, that is it is relatively easy to study subsistence patterns, more difficult to study social organization, and most difficult to study ideology (Hawkes 1954: 155168). Until now, the principal method employed by Chinese archaeolo- 
gists in the study of early states is still typology, which has been commonly used to do periodization and analyze subsistence patterns. To solve the issue of social organization, archaeologists have to adjust their perspective and adopt alternative approaches. Due to dated methodology, detailed analyses reflect these critical shortcomings to deal with the issue of social change.

Thus, we can understand why the inference made by Chinese archaeologists, i.e. the Erlitou Cuture $=$ the Xia Culture $=$ the Xia nationality $=\mathrm{a}$ group of unique artifacts = the Xia State $=$ the Xia territory, can't be accepted by overseas scholars.

\subsection{Application of Historical Documents}

From the previous review, we can see that Chinese archaeologists have corresponded archaeological discoveries to historical documents without the slightest critical evaluation in the study of the Xia. Written records undoubtedly contribute more to our knowledge of the past than cultural remains in archaeological research, because these could directly provide historical evidence without needing to extract information from archaeological data. However, using written records without scrutiny will certainly incur criticism.

First of all, regardless of the truth of the Xia Dynasty in historical documents, it is unwarranted to confirm that Xia was the earliest state. We are not sure whether a 'state' as mentioned by Sima Qian is same as the concept of 'state' defined by modern social sciences - there are similar instances from around the world. There are obvious difference between Chinese and overseas scholars in dealing with the concept of 'state' in historical documents.

One instance is the question of kingship in Anglo-Saxon England. The Anglo-Saxon Chronicle, which took final shape in about $1155 \mathrm{AD}$, refers to kings of around 1155 AD. It is easy for the historian to think of kings and states at that period. However the archaeology strongly suggests that a full state society did not emerge until the time of King Offa of Mercia in around $780 \mathrm{AD}$, or perhaps King Alfred of Wessex in 871 AD. 'State' in written records is actually the chiefdom in terms of modern scientific terminology (Renfrew and Bahn 2012: 180).

Another instance is ancient Egypt. The historian has usually believed that the formation of the ancient Egyptian state started from Dynasty 0 with the political union of Upper and Lower Egypt was achieved. However, independent archaeological survey reveals that Narmer's conquest of Buto in the Delta seems to have created only a more territorially extensive version of the southern chiefdom and many of the anthropological characteristics of states did not appear until the second Dynasty (Savage 2001: 134).

According to one opinion, the earliest mention of a Xia Dynasty occurred in the Western Zhou sections of the Shangshu (尚书; The Book of Documents), that purport to be speeches of the Duke of Zhou. One credi- 
ble interpretation of those speeches holds that the Xia Dynasty was a historical fiction invented by the early Zhou rulers to justify their overthrow of the Shang Dynasty. In addition, the oracle texts give no sign that the Shang kings saw themselves as heirs to Xia legitimacy (Bagley 1991: 214-255). Another opinion is that the earliest written records of the Xia appeared in the 'Bamboo Annuals' that had been unearthed from an ancient tomb at Ji County of Emperor Wu Di of the Jin Dynasty. Historians regarded it as the chronicle of the Wei State which took shape around the mid-Warring States period (X. Li 1997: 47). Even if we suppose that the documents were completed in the twentieth year the reign of King Xiang of the Wei State (299 AD), it is still 1000 years later than the Xia. Even if the truth of the Xia was supported, the question of how we deal with and use these written records within a temporal interval of about 1000 years has to be treated with caution.

Renfrew and Bahn pointed out that while written records undoubtedly contribute greatly to our knowledge of the society in question, but one should not accept them uncritically at face value. The great risk with historical record is that they can impose their own perspective, so that they begin to supply not only the answers to our questions, but subtly to determine the nature of those questions and even out concepts and terminology (Renfrew and Bahn 2012: 180).

Bagley also claimed that written history holds a double danger for archaeology. Not only does it steer the archaeological sample toward conformity with tradition by telling archaeologists where to look, it also tells us what to see (Bagley 1991: 227-28).

Without the testimony of the credibility of written records, Chinese scholars have employed them as convincing data to calculate the beginning of the Xia, corresponded it with radiocarbon dates, set up the reign table of kings of the Xia, and corresponded excavated city sites with capitals of kings of the Xia. It is nothing strange that their conclusion was called in question abroad.

\subsection{Testifying Procedure}

There is a tendency to oversimplify in the archaeological exploration of early states in China. For instance, if they find the large foundation of architectures, they suggest the presence of a king or a state. If they once see rammed earth walls, they postulate the presence of a city or a capital and try to correspond them to written records. If they once find rich burials, they regard them as the evidence of a class society. If they once come across attendant burials or remains of abnormal corpses, they regarded them as sacrificial or immolated burials and as the evidence of a slave society. Bronze vessels and jade artifacts are taken as the evidence of ritual institution and formation of royal rule. Writing characters are regarded as the emergence of civilization. There is no scientific definition 
given to such major concepts as state and royal power. As soon as they need theoretical support, a well-worn quotation from Marx, Engels and Morgan is added. No attempt has been made to discuss how to identify social patterns of a state from archaeological data.

Actually, there are many alternatives between cultural circumstances and their causes, which never show a monogenetic, stiff and mechanical relationship. If we were consider anthropological and archaeological data from around the world, we may find many exceptions. Chinese scholars used to look at these issues in terms of historical perspective and seldom consider the complexity and diversification of human behavior and cultures. Therefore, as soon as they find a phenomenon, they intend to look it as the evidence of historical events.

Thorp questioned the explanation of some phenomena at the Erlitou site. For example, he pointed out that it was inappropriate to regard large rammed earth foundations as a palace and that there is little artifectual evidence with which to determine the actual use of any of these sites. It may be more appropriate to identify such large walled compounds as 'palace-temples' to acknowledge their probable mixed functions. On the basis of the setting of palace in early texts, the Erlitou yards are single spatial units and unable to arrange them all to meet in a court-yard, unlike the environment inferred from the Western Zhou document. Thus, the Erlitou site may have functioned as a ceremonial center.

Thorp also criticized Chinese extrapolations about social structure on the basis of the three sizes of Erlitou burials. There are a few large tombs unearthed at Erlitou. If an extensive cemetery tract containing large tombs were found, it would heighten speculation that this was a royal site. Furthermore, the extent and volume of funerary objects at the Taosi site in Shanxi and the Liangzhu sites in Zhejiang and Jiangsu certainly dwarf the reported remains at Erlitou.

In terms of material objects, Thorp questioned the Chinese scholars' position that bronze and jade objects were the symbol of royal power. He said that they go so far to regard the possession of metal vessels as a defining attribute of royal power. If these crafts are taken as indexes of social complexity, is there any compelling reason to look for an incipient state only among bronze-using cultures? (Thorp 1991: 1-38)

There is a need to listen to Beveridge's warning that it would be totally inappropriate to deal with complicated issues merely by using traditional method, common sense and intuited judgment (Beveridge 1987: 99).

\subsection{Normative versus Idiographic Explanations}

Up to the present, the study of the early states in China has focused on historiographic issues and never tried to explain the process of social change. Hence scholars have been satisfied by identifying where, when and what of early states in China and never considered the dynamics of their origins. K.C. Chang felt deeply vexed at this situation: why Chinese 
scholars confined the origin of Chinese civilization only to where Chinese civilization came from? Why not to discuss internal dynamics in the societies before civilization? (Chang 1997: 3-4) Judging from the profundity of the research, the study of early states in China only constituted an idiographic explanation and unable provides normative explanation of social sciences with valuable generalizations.

Once dealing with the issue of exploring the issue of social change, we need theories. Due to the strong historiographical orientation of Chinese archaeology, the role of theory in archaeological research has been totally ignored. The deficiency of theory has directly affected research designs and the interpretation of data. Without systematic theoretical exploration, Chinese scholars could only look for questions from historical documents and make conclusions based on their own experiences and intuitive senses. The conclusions derived from intuitive judgments and experiences are less convincing both in their interpretation and the depth of studies. It is hard to avoid heated controversy on this issue.

As a matter of fact, an exploration of the regularity of social change could promote research, attain a deeper understanding of the causes, essential aspects and characteristics of early states and realize the process and profound dynamics of the formation of early states.

Judging from the scientific values of the West, the normative explanation has been the key issue of scientific research, because understanding an object of the study possesses a general significance world-widely. The ideographic approach focusing on individual event based on written records differs tremendously from normative studies in the West. This contrast has caused further difference on the research of Erlitou and Xia between Chinese and overseas scholars.

\section{CONCLUSION}

There has been a heated debate concerning the relationship between the Erlitou Culture and the Xia Dynasty. Most Chinese scholars and a few overseas colleagues agree that the Erlitou Culture was the representative or the materialized manifestation of the Xia State. Whereas most overseas scholars insist that without coexisted written evidence, it can't be assured that Erlitou is the factual basis of the Xia or we could affirm dynastic status of the Xia in historical documents based on archaeological discoveries. This article analyzes the reason of this intellectual difference that can be attributed to the difference between Chinese and overseas scholars in epistemology, methodology, paradigm and orientation. Being able to confirm historical documents with archaeological discoveries has been regarded by many Chinese archaeologists as the most contributive achievement of Chinese historiography. This is the reason why Chinese scholars have persisted in corresponding the Erlitou Culture to the Xia Dynasty. Liu Li also mentions the Sino-Western academic difference 
caused by basic concepts and methodologies. According to Liu, the biggest problem is that Chinese scholars tend to equalize archaeological cultures defined by artifact typology with ethnic groups and polities recorded in historical documents without realizing they are two different concepts and need different demonstrating methods. She points out that the distribution of the Erlitou Culture and its process of social complexity does not coincide with the rise of the Xia Dynasty around 2,100 BC as documents recorded (Liu L. 2004: 223-224). Based on recent research on settlement archaeology, urbanization, craft specialization, and social stratification, Liu Li and Chen Xingcan argue that a state-leveled political organization might have appeared in the second phase of the Erlitou. They tend to designate this early state before the Shang Dynasty as 'the Erlitou State' rather than 'the Xia Dynasty' (Liu L. and Chen 2012: 262). Therefore, historical documents and archaeological materials are different evidence that being best studied separately according to their concepts and methods. Having rethought the debate on the Erlitou-Xia relations, Liu Li and $\mathrm{Xu}$ Hong pointed out that much attentions of Chinese scholar was placed on its ethnic and dynastic affiliation. Little attention has been paid to some critical issues such as craft production, agricultural practice, urban population parameter, and urban-rural interaction. They urged that Chinese scholars should use rich archaeological data to understand the process of state formation by means of multidisciplinary research (Liu L. and Xu 2007: 886-901). For now, there is needless to correspond the Erlitou Culture with the Xia Dynasty. As a matter of fact, current archaeology is able to explore the formation and development of early Chinese states independently. Historical documents are merely useful evidences, Instead of obsessing the debate whether the Erlitou site is the Xia capital or not, historians should make effort to rewrite the formation process of early Chinese states by using new evidence provide by archaeological findings.

\section{ACKNOWLEDGEMENT}

We greatly appreciate for the English proofreading of this article made by Ms Ilse Schache during her teaching at Fudan University.

\section{REFERENCES}

An, Jinhuai. 1983. New Archaeological Achievements of the Xia and Shang of Henan in Recent Years. Archaeology (考古), 3: 1-7.

Bagley, R.W. 1991. Changjiang Bronze and Shang Archaeology. In Proceedings of the International Colloquium on Chinese Art History, Antiquities. Part 1 (pp. 214-255). Taipei: National Palace Museum.

Beveridge, W. I. B. 1980. Seed of Discovery: A Sequel to the Art of Scientific Investigation. London: Heinemann Educational Books.

Chang, K. C. 1997. Preface. In A Study of the History Chinese Prehistoric Archaeology 1895 1949. Beijing: JDX Joint Publishing Company. 
Chang, K. C. 2011. Preface. In Chinese Version of Time and Tradition. Beijing: Renmin University of China Press.

Chen, Ning. 2003. The Dispute of 'the the Xia, Shang and Zhou Dynasties Chronology Project' is Hardly Subsided. Social Sciences Weekly (社会科学报), Nov. 27.

Chen, Xingcan, Liu Li, Lee Yun-Kuen, Wright, H. T., and Rosen A. M. 2003. Development of Social Complexity in the Central China: Research into the Settlement Pattern in the Yiluo River Valley. Acta Archaeologica Sinica (考 古学报), 2: 161-217.

Cheng, Pingshan. 2001. Brief Discussion on the Origin of the Erligang Culture. Huaxia Archaeology (华夏考古), 4: 88-93, 105.

Du, Jinpeng. 1993. New Exploration of the Age of the Xia and Shang Cultures. Cultural Relics of Central China (中原文物), 1: 12-18.

Fan, Wenlan. 1978. A General Introduction to Chinese History. Beijing: People's Publishing House.

Fang, Yanming. 2001. Several Issues of the Study of the Early Xia Culture. Cultural Relics of Central China, 4: 46-50.

Field team of Erlitou from the Institute of Archaeology, Chinese Academy of Social Sciences. 1961. A Brief Report of the Test Excavation at Erlitou, Yanshi in 1959. Archaeology, 2: 82-85, 81.

Field team of Erlitou from the Institute of Archaeology, Chinese Academy of Social Sciences. 1965. A Brief Report of the Excavation at the Erlitou Site in Yanshi, Henan. Archaeology, 5: 215-224.

Field team of Erlitou from the Institute of Archaeology, Chinese Academy of Social Sciences. 1974. The Excavation Report of an Early Shang Palace Site at Erlitou in Yanshi, Henan. Archaeology, 4: 234-238.

Field team of Erlitou from the Institute of Archaeology, Chinese Academy of Social Sciences. 1980. A Brief Excavation Report of Erlitou in 1980, Yanshi, Henan. Archaeology, 3: 119-205.

Field team of Erlitou from the Institute of Archaeology, Chinese Academy of Social Sciences. 1983. The Second Palace Site at Erlitou in Yanshi, Henan. Archaeology, 3: 206-216.

Field team of Erlitou from the Institute of Archaeology, Chinese Academy of Social Sciences. 1984. A Brief Excavation Report of III Area from 1980 to 1981 at the Erlitou Site, Yanshi. Archaeology, 7: 582-593.

Field team of Erlitou from the Institute of Archaeology, Chinese Academy of Social Sciences. 1985. A Brief Excavation Report of IX Area at the Erlitou Site in 1982, Yanshi. Archaeology, 12: 1085-94, 1108.

Field team of Erlitou from the Institute of Archaeology, Chinese Academy of Social Sciences. 1992. A Brief Excavation Report of Tombs at the Erlitou Site in 1987, Yanshi. Archaeology, 4: 294-303.

Harris, M. 1979. Cultural Materialism: the Struggle for a Science of Culture. New York: Random House.

Hawkes, C. F. 1954. Archaeological Theory and Method: Some Suggestions from the Old World. American Anthropologist, 56: 155-168. 
Institute of Cultural Relics of Henan, and Department of Archaeology of Museum of Chinese History. 1983. Excavation at the Wangchenggang Site, Dengfeng. Archaeology, 3: 8-16.

Johnson, M. 1999. Archaeological Theory, An Introduction. Oxford: Blackwell Publishers.

Li, Boqian. 1986. Cultural Nature of the Erlitou and Its Ethnicity. Cultural Relics (文物), 6: 41-47.

Li, Weiming. 2002. Remain of the First Phase of the Erlitou Culture and the Origin of the Xia Culture. Cultural Relics of Central China, 1: 33-42.

Li, Xueqin. 1997. Ancient Version of Bamboo Annuals and the Xia History. In Going out of the Age of 'Doubt of the Old'. Shenyang: Liaoning University Press.

Lin, Dingyi. 1986. An Introduction to Scientific Research Methods. Hangzhou: Zhejiang People's Press.

Liu, Li. 2004. The Chinese Neolithic: Trajectories to Early States. Cambridge: Cambridge University Press.

Liu, Li. 2009. Academic Freedom, Political Correctness and Early Civilization in Chinese Archaeology: the Debate on Xia-Erlitou Relations. Antiquity 83: 83143. Liu, Li and Chen Xingcan.

Liu, Li. 2012. The Archaeology of China: from the Late Paleolithic to the Early Bronze Age. Cambridge: Cambridge University Press.

Liu, Li and Xu, Hong. 2007. Rethinking Erlitou: Legend, History and Chinese Archaeology. Antiquity 81: 886-901.

Liu, Xing. 2001. Absent Dialogue - the Dispute on 'the Xia, Shang and Zhou Dynasties Chronology Project' abroad. Chinese Cultural Relics News (中国文 物报), June 6 .

Liu, Xu. 1986. Analysis of the nature of the Erlitou Culture and its Relationship with the Shang Culture of the Erligang Period in Terms of Pottery from Tombs. Cultural Relics, 6: 48-54.

Qiao, Yu. 2010. Development of Complex Societies in the Yiluo Region: A GIS Based Population and Agricultural Area Analysis. Acta Archaeologica Sinica, Vol. 4: 423-454.

Renfrew, C., and Bahn, P. 2012. Archaeology: Theories, Methods and Practice. New York: Thames and Hudson.

Savage, S. H. 2001. Some Recent Trends in the Archaeology of Predynastic Egypt. Journal of Archaeological Research 9 (2): 101-155.

Thorp, R. L. 1991. Erlitou and the Search for the Xia. Early China, 16: 1-38.

Tian, Changwu. 1999. On the Chronological Issue of Ancient Chinese History. Yindu Journal (殷都学刊), 4: 33-37.

Tong, Zhuchen. 1975. Discussion of the Origin of Early States in China on theBasis of the Erlitou-type Culture. Cultural Relics, 6: 29-33, 84.

Trigger, B. G. 1978. Time and Tradition. Edinburgh: Edinburgh University Press. 
Wu, Ruzuo. 1978. On Preliminary Exploration of the Xia Culture. Cultural Relics, 9: 70-73.

Xia, Nai. 1978. On Several Issues of Exploring the Xia Culture. Communications of Henan Cultural Relics and Museology (河南文博通讯), 1: 32-33.

Xie, Weiyang. 1995. The Incipient States of China. Hangzhou: Zhejiang People's Press.

Xu, Hong, Chen Guoliang, and Zhao Haitao. 2005. A Preliminary Study into the Settlement Pattern of the Erlitou Site. In Du, Jinpeng and Xu Hong (eds.), Research on the Erlitou Remains in Yanshi (pp. 484-493). Beijing: Science Press.

Xu, Xusheng. 1959. Preliminary Report on the Field Survey of 'Ruin Xia' in the Southern Henan in 1959. Archaeology, 11: 592-600.

Yang, Yubin. 2002. Xia, Shang and Zhou Chronology Project and the Study of the Xia and Shang Culture. Huaxia Archaeology, 2: 101-06, 112.

Zhang, Juqing. 1988. Art of Scientific Research: Introduction of Scientific Methodology. Wuhan: Hubei People's Press.

Zhao, Zhiquan. 1978. Retrospect and Prospect of the Exploration of the Xia Culture Conducted by Archaeological Team of Erlitou. Communications of Henan Cultural Relics and Museology, 3: 9-11, 13.

Zhao, Zhiquan. 1986. On the Origin of the Erlitou Culture. Acta Archaeologica Sinica, 1: 1-19.

Zhao, Zhiquan. 1987. Discussion on that the Erlitou Culture Might Have Been the Capital of the Late Xia Dynasty. Huaxia Archaeology, 2: 196-204.

Zheng, Guang. 1985. On the Early Shang Culture at Erlitou. In Proceedings of the Fourth Conference of the Association of Chinese Archaeology, pp. 18-24. Beijing: Cultural Relics Press.

Zheng, Ruokui. 1994. On Burials of the Erlitou Culture Type. Huaxia Archaeology, 4: 63-81.

Zhu, Lingling. 1998. The Territory of the Xia Dynasty. Journal of Historical Science, 4: 16-22.

Zhuang, Chunbo. 1990. The Erlitou Culture and the Xia Chronology. Journal of Historical Science, 2: 1-7.

Zou, Heng. 1979. Several Issues of the Exploration of the Xia Culture. Cultural Relics, 3: 64-69.

Zou, Heng. 1980. Preliminary Discussion of the Xia Culture. In Archaeological Essays of Xia, Shang and Zhou. Beijing: Cultural Relics Press.

Zou, Heng. 1990. Retrospect and Prospect of the Study of the Xia Culture. Cultural Relics of Central China, 2: 1-12. 